\title{
PENGARUH EXPERIENTIAL SHARING TERHADAP KINERJA BISNIS MELALUI INOVASI PRODUK SEBAGAI VARIABEL INTERVENING
}

\author{
Fauji Sanusi ${ }^{1}$ \\ Universitas Sultan Ageng Tirtayasa \\ fauzi.sanusi@yahoo.com \\ Gerry Ganika ${ }^{2}$ \\ Universitas Sultan Ageng Tirtayasa \\ gega@untirta.ac.id
}

Diterima 21 April 2020

Disetujui 20 Mei 2020

\begin{abstract}
Internal problems of small and medium enterprises (SMEs) have been extensively studied, especially those related to low level of knowledge and skills of their workforce, thus impacting company's business performance. This study aims to examine whether experiential sharing can improve business performance of SMEs through product innovation as an intervening variable. This research develops a concept of experiential sharing or sharing experiences as a process that can improve a company's business performance through product innovation variables. This study show that experiential sharing will have a stronger influence on company's business performance if it is mediated by product innovation. Samples taken in this study were 173 managers and / or metal casting SME owners in Central Java. To test research hypothesis, data is processed by using Smart PLS. Experiential sharing can directly influence product innovation and business performance of SMEs. Similarly, product innovation can directly affect business performance and can partially mediate relationship between experiential sharing and business performance. SMEs can improve business performance by increasing experiential sharing as a antecendent factor. In addition, experiential sharing can improve product innovation which can then improve the performance of SME businesses.
\end{abstract}

Keywords: experiential sharing, innovation, business performance, partial least square 


\section{PENDAHULUAN}

Budaya berbagi pengetahuan merupakan salah bentuk dari budaya interaksi sosial dalam organisasi. Budaya ini berkembang melalui berbagai aktivitas pertukaran pengalaman dan keterampilan karyawan dalam organisasi (Hogel, 2003; Lin, 2007). Penyebaran pengetahuan dan pengalaman antar individu dalam kelompok kerja memiliki efek yang signifikan terhadap operasi perusahaan, karena dapat meningkatkan kompetensi karyawan dan dapat menghasilkan pengetahuan baru dalam perusahaan (Baum \& Ingram, 1998; Karl Erik Sveiby \& Simon, 2002).

Sejumlah penelitian telah membuktikan bahwa berbagi pengetahuan sangat penting bagi organisasi karena dapat meningkatkan kinerja inovasi dan mengurangi biaya belajar (Calantonea, Cavusgila, \& Zhao, 2002; Lin, 2007; Scarbrough, 2003). Selain itu, Wang and Wang (2012), membuktikan bahwa berbagi pengetahuan diseluruh organisasi bermanfaat untuk mempertahankan nilai-nilai perusahaan, belajar teknik-teknik baru, memecahkan masalah yang dihadapi, menciptakan kompetensi inti dan memprakarsai situasi baru serta meningkatkan kualitas dan kecepatan dalam berinovasi. Berbagi pengetahuan akan mengubah pengetahuan organisasi menjadi pengetahuan individu atau kelompok melalui proses internalisasi dan sosialisasi. Proses berbagi pengetahuan yang dilakukan melalui bermacam kegiatan seperti pelatihan, presentasi, interaksi dengan konsumen dan pemasok, seluruhnya terbukti mampu meningkatkan kinerja bisnis perusahaan. Penelitian lainnya membuktikan bahwa perusahaan yang memanfaatkan pengetahuan akan dapat meningkatkan asset pengetahuan organisasi sehingga dapat mengembangkan inovasi produk dan layanan baru untuk memenuhi pasar mereka (Liao, Wang, Chuang, Shih, \& Liu, 2010; Nguyen, Ngo, Bucic, \& Phong, 2018; Wang, Sharma, \& Cao, 2016; Wang \& Wang, 2012). Namun demikian riset-riset tentang berbagi pengetahuan yang berkaitan dengan kinerja bisnis, terutama pada sektor Usaha Kecil Menengah (UKM) masih sangatlah sedikit.

Di Indonesia, peran UKM sangatlah penting. Terbukti pada saat krisis moneter 1997 Asia dan krisis keuangan global 2008, UKM di Indonesia mampu menyokong sendi perekonomian. Dalam kondisi krisis, UKM mampu bertahan dan mampu menggerakkan perekonomian rakyat (Berry, Rodriguez, \& Sandee, 2001). Merujuk pada dinamika global yang cepat berubah, yang didorong oleh kemajuan teknologi informasi seperti saat ini. Maka UKM diseluruh dunia dituntut untuk dapat meningkatkan kompetensi dan keahliannya dengan cara memfokuskan proses bisnisnya pada terciptanya pengetahuan dan atau kapabilitas strategi dalam organisasinya $(\mathrm{Li}$, Huang, \& Tsai, 2009), tak terkecuali bagi UKM di Indonesia.

Drucker (1993) telah memprediksi bahwa keunggulan bersaing di masa yang akan datang (saat ini) sangat ditentukan oleh adanya sumber daya pengetahuan yang dimiliki oleh perusahaan atau yang lebih dikenal dengan pekerja pengetahuan (knowledge worker). Efektivitas perusahaan sangat tergantung pada seberapa baik pengetahuan yang dimiliki dapat dibagikan antar individu, pada tim atau unit dalam organisasi. Berbagai penelitian menunjukkan bahwa berbagi pengetahuan akan memiliki kontribusi terhadap kapabilitas organisasi, seperti inovasi yang menjadi salah satu faktor yang sangat penting dalam meningkatkan kinerja bisnis (Atalay, Anafarta, \& Sarvan, 2013; Hendry \& Erwin, 2014; Rajapathirana \& Hui, 2018; Soto-Acosta, Popa, \& Palacios-Marqués, 2017). Secara spesifik, Wu, et al., (2019) menjelaskan bahwa berbagi pengetahuan yang bersumber dari pengamalan (experiential sharing) merupakan aspek penting dalam membentuk strategi jasa yang berorientasi pada pasar. 
Polanyi (1962) membagi ilmu pengetahuan kedalam dua dimensi yaitu pengetahuan tacit dan pengetahuan explicit. Pengetahuan tacit dapat dipahami tetapi tidak dapat dinyatakan secara eksplisit karena jenis pengetahuan ini tersimpan dalam pikiran seseorang sebagai akumulasi dari pengalaman (experiences), akumulasi kegiatan dan keterlibatannya dalam pekerjaan tertentu.

Pembahasan mengenai berbagi pengetahuan khususnya pengetahuan tacit yang babasis pada pengalaman (experiential sharing) untuk membangun keunggulan bersaing perusahaan masih jarang ditemukan dalam berbagai literatur. Namun demikian, konstruk berbagi pengetahuan tacit terbukti manfaatnya dalam pengembangan kapabilitas perusahaan (Alam, Endres, Lee Endres, \& Chowdhury, 2007; Alwis \& Hartmann, 2008; Mayfield, 2010). Meskipun beberapa peneliti lain memberikan bukti bahwa praktek berbagi pengetahuan tidak langsung mengarah pada peningkatan kinerja organisasional, akan tetapi kinerja bisnis atau kinerja organisasional mungkin dapat ditingkatkan melalui upaya-upaya inovasi yang dipengaruhi oleh aktivitas berbagi pengetahuan.

\section{TINJAUAN PUSTAKA \\ 2.1. Resource Based View}

Berbasis pada teori resource based view of the firm (RBV) yang digagas oleh Penrose (1959) dan selanjutnya dikembangkan oleh Wernerfelt (1984) dan Barney (1991), bahwa sumber daya akan memiliki nilai strategis apabila memenuhi beberapa kriteria, yaitu jika sumber daya tersebut bernilai (valueable), langka (rare), sulit ditiru (inimitable) dan sulit digantikan. RBV memiliki keunggulan dari segi nilai ekonomis dan dapat menjadi faktor penentu dari suatu keunggulan bersaing yang berkesinambungan (Fahy, 2000). Hal ini juga akan membantu menjelaskan mengapa beberapa sumber daya yang ada akan lebih memberikan keuntungan atau keunggulan dibandingkan jenis sumber daya lainnya. Disamping itu pendekatan RBV juga dapat menjelaskan mengapa sumber daya harus bersifat unik sehingga akan memberikan hasil akhir berupa pencapaian keunggulan bersaing yang dapat bertahan lama atau berkesinambungan meskipun dalam kondisi persaingan terbuka.

Sumber daya yang sesuai dengan kriteria RBV disebut sebagai asset oleh Capron and Hulland (1999), serta mendefinisikannya sebagai sekumpulan pengetahuan, asset fisik, manusia dan faktor-faktor berwujud dan tidak berwujud lainnya yang dimiliki atau dapat dikendalikan oleh perusahaan, yang memungkinkan perusahaan untuk menghasilkan barang dan jasa untuk ditawarkan ke pasar secara efektif dan efisien. Helfat and Peteraf (2003) mendefinisikan sumber daya sebagai asset atau input baik berwujud maupun tidak berwujud yang dimiliki dan dikendalikan oleh perusahaan atau memiliki akses lainnya untuk melakukan kegiatan produksi. Sejalan dan itu, Wheelen, Hunger, Hoffman, and Bamford (2014) menyebutkan bahawa asset tersebut dapat berbentuk kompetensi, proses, keahlian atau pengetahuan yang dapat dikendalikan oleh perusahaan. Sehingga pengetahuan tacit yang berbasis pada pengalaman kerja (work experience) para pegawai dapat dikategorikan sebagi asset perusahaan yang dapat dikelola oleh perusahaan. 


\subsection{Manajemen Pengetahuan}

Definisi manajemen pengetahuan masih sangat bervariasi diantara para peneliti, namun secara umum dapat dikategorikan menjadi tiga perspektif (Handtrack, 2009). Pertama, manajemen pengetahuan dipandang sebagai asset, kedua, manajemen pengetahuan sebagai tujuan dan ketiga, manajemen pengetahuan dipandang sebagai suatu proses.

Para ahli yang fokus pada manajemen pengetahuan sebagai asset berpendapat bahwa manajemen pengetahuan adalah tentang bagaimana sebuah organisasi melindungi, melakukan koordinasi, kodifikasi, menyebarkan, mengembangkan dan menerapkan sumber daya pengetahuan yang tidak berwujud untuk menciptakan nilai (Earl, 2001; Liebowitza \& Megbolugbe, 2003; Stovel \& Bontis, 2002; Karl Erick Sveiby, 1997; Wickramasinghe, 2003). Manajemen pengetahuan dapat berupa pengalihan asset pengetahuan antar individu dalam organisasi (Shankar \& Gupta, 2005). Kakabadse, Kakabadse, and Kouzim (2003) berpendapat bahwa manajemen pengetahuan adalah formalisasi dan akses terhadap pengalaman dan keahlian. Sementara itu Davidson and Voss (2002) berpendapat bahwa manajemen pengetahuan adalah upaya menciptakan sistem yang memungkinkan organisasi untuk memanfaatkan pengetahuan, pengalaman dan kreativitas staf mereka. Sehingga tidak diragukan lagi bahwa pengalaman (experience) staf adalah asset bagi perusahaan yang perlu dikelola.

Proses pengalihan/berbagi asset pengetahuan (sharing knowledge) dapat dilakukan melalui proses interaksi interpersonal dan interaksi antara pengetahuan eksplisit dan tacit (I. Nonaka, \& Takeuchi, H, 1995; I. Nonaka, Toyama, \& Nagata, 2000), yang dapat berupa proses sosialization, externalization, combination dan internalization (SECI model). Bock and Kim (2002) berpendapat bahwa sharing pengetahuan merupakan bagian terpenting dalam manajemen pengetahuan. Jika menggunakan perspekstif $R B V$, maka tujuan utama aktivitas sharing pengetahuan adalah menjadikan pengetahuan sebagai asset organisasi dan pengembangan sumber daya perusahaan (Dawson, 2001) yang bertujuan untuk menciptakan nilai tambah bagi perusahaan..

Praktek berbagi pengetahuan diseluruh organisasi sangat penting untuk mempertahankan nilai-nilai perusahaan, untuk belajar teknik-teknik baru, memecahkan masalah yang dihadapi perusahaan, menciptakan kompetensi inti dan memprakarsai situasi baru (Wang et al., 2016; Wang $\&$ Wang, 2012). Interaksi langsung adalah sarana utama dalam proses berbagi pengetahuan tacit, yang didasari oleh kemauan (willingness) atau keinginan karyawan untuk melakukan sharing pengetahuan (Bock \& Kim, 2002). Oleh karenanya, aktivitas berbagi pengalaman (experiential sharing) antar staf merupakan bagian dari manajemen pengetahuan dalam perusahaan.

\subsection{Inovasi}

Barnett (1953) secara sederhana mendefinisikan inovasi sebagai pengenalan sesuatu yang baru. Thompson (1965) memberikan definisi lebih luas yaitu inovasi merupakan sebuah pembaharuan, penerimaan dan pelaksanaan ide-ide baru, proses baru, barang dan jasa baru. Amabile, Conti, Coon, Lazenby, and Herron (1996) mendefinisikan inovasi sebagai keberhasilan pelaksanaan ide-ide kreatif dalam organisasi. Sebuah definisi yang lebih komprehensif disampaikan oleh West (1990), mereka mendefinisikan inovasi sebagai upaya menyampaikan sesuatu yang baru secara terencana, aplikasi produk baru, proses, prosedur, atau ide-ide baru yang dirancang untuk memberikan manfaat bagi individu, kelompok, organisasi atau masyarakat yang lebih luas. Sedangkan Damanpour (1991) mendefinisikan inovasi sebagai alat atau sarana untuk mengubah sebuah organisasi, baik sebagai respon terhadap perubahan lingkungan internal maupun eksternal atau sebagai antisipasi untuk mempengaruhi lingkungan. 
Peran pengetahuan sebagai intangible asset terhadap inovasi sangatlah penting. Pengetahuan yang dimiliki perusahaan sebagai hasil hubungan dan komunikasi yang intensif baik antara karyawan maupun dengan pihak luar yang memiliki keahlian dibidangnya akan menambah kompetensi perusahaan. Rothwell (1991) melakukan penelitian terhadap perusahaan kecil dan menengah di Eropa, menemukan bahwa karyawan dalam perusahaan yang secara intensif melakukan hubungan dengan pihak eksternal untuk melakukan pertukaran ilmu pngetahuan, akan memiliki keberhasilan dalam proses inovasi. Berbagai penelitian telah membuktikan bahwa salah satu faktor penentu dalam inovasi adalah proses berbagi pengetahuan (Kamasak \& Bulutlar, 2010; Liao et al., 2010; Soto-Acosta et al., 2017).

\section{HIPOTESIS PENELITIAN}

\subsection{Hubungan Experiential Sharing dan Kinerja Bisnis}

Penelitian Wang, Y.\& Lin, J. (2013) membuktikan orientasi manajemen pengetahuan dapat meningkatkan kinerja perusahaan. Pengalaman (experience) sebagai bagian dari pengetahuan tacit individu perlu untuk didiseminasikan kepada staf yang lain agar pengalaman tersebut menjadi asset yang mampu meningkatkan nilai perusahaan, proses diseminasi pengalaman ini dapat disebut sebagai experiential sharing. Berbagai penelitian telah membuktikan bahwa berbagi pengetahuan dapat meningkatkan kinerja bisnis perusahaan (Nguyen et al., 2018; Soto-Acosta et al., 2017; Wang et al., 2016; Wang \& Wang, 2012), sehingga aktivitas berbagi pengetahuan yang berbasis pada pengalaman (experiential sharing) akan mampu meningkatkan kinerja bisnis perusahaan.

\section{H1 : Terdapat hubungan yang positif antara experiential sharing dengan kinerja bisnis}

\subsection{Hubungan Experiential Sharing dengan Inovasi}

Dari sudut pandang teori keunggulan berbasis pengetahuan, berbagi pengetahuan merupakan faktor penting dalam membangun keunggulan bersaing (Nguyen et al., 2018; SotoAcosta et al., 2017; Wang et al., 2016). Berbagi pengetahuan yang didukung stimulus intelektual yang proaktif dari pimpinan akan mendorong terciptanya pengetahuan baru yang dapat dijadikan sebagai sumberdaya untuk memecahkan masalah-masalah yang ada di perusahaan, menciptakan proses produksi yang lebih efisien. Bahkan ketika pengetahuan ditransfer diantara kelompokkelompok dalam organisasi, ide-ide yang ada dari satu kelompok akan memunculkan ide baru untuk yang lain melalui proses komunikasi dan berbagi informasi (Ganika, 2016), demikian pula sebaliknya, sehingga akan berpotensi adanya pengenalan produk atau jasa yang baru bagi pelanggan (Hargadon (1997).

Peran pengetahuan tacit dalam manajemen inovasi sudah dibuktikan melalui beberapa penelitan. Keunggulan kompetitif melalui inovasi akan diperoleh ketika perusahaan mengelola pengetahuan tacit karyawan dengan baik. Pengetahuan tacit dapat menjadi sumber dari sejumlah peluang dan potensi menuju penemuan ide-ide baru dan kreativitas (Alwis \& Hartmann, 2008). Beberapa peneliti lain membuktikan bahwa pengetahuan adalah unsur yang paling penting dalam inovasi (Kamasak \& Bulutlar, 2010; Lin, 2007; Soto-Acosta et al., 2017). Berbagi pengetahuan dengan dimensi knowledge collecting dan knolwedge donating memiliki efek yang signifikan terhadap seluruh type inovasi (Kamasak and Bulutlar (2010) dan Lin (2007). Sehingga experiential sharing yang dilakukan secara langsung akan berpengaruh pada tingkat kreativitas tim yang lebih tinggi dan menghasilkan produk yang berbeda (Gino, Argote, Spektor, and Todorova (2010). 


\section{H2 : Terdapat hubungan yang positif antara experiential sharing dengan inovasi produk}

\subsection{Hubungan Inovasi dan Kinerja Bisnis}

Inovasi telah diakui sebagai faktor pendorong yang cukup penting bagi perusahaan untuk menciptakan nilai dan mempertahankan keunggulan kompetitif dalam lingkungan eksternal yang semakin kompleks dan cepat berubah (Bilton \& Cummings, 2010; Subramaniam \& Youndt, 2005).

Dari sudut pandang teori yang berbasiskan pada keunggulan sumber daya, kompetensi atau kecakapan yang sifatnya inovatif dalam perusahaan, dapat dijadikan kekuatan untuk mencapai keunggulan bersaing. Kompetensi yang memiliki akar sangat kuat dalam organisasi dan tidak dapat dijelaskan secara eksplisit ataupun ditiru oleh perusahaan pesaing, akan menentukan keunggulan perusahaan dalam persaingan. (Barney, 1991; Hunt \& Morgan, 1996).

Berbagai hasil penelitian empiris menunjukkan bahwa inovasi yang dilakukan perusahaan akan dapat meningkatkan kinerja bisnis. Hult, Hurley, and Knight (2004) dalam penelitiannya menemukan bahwa inovasi secara positif berkaitan dengan kinerja perusahaan. Inovasi yang dilakukan oleh UKM secara fokus, baik yang bersifat radikal maupun incremental, berhubungan positif dengan kinerja perusahaan (Oke, Burke, \& Myers, 2007). Penelitian Calantonea et al. (2002) membuktikan bahwa perusahaan dengan inovasi yang lebih besar akan lebih berhasil dalam merespon kebutuhan pelanggan sehingga perusahaan dapat mengembangkan kemampuan baru yang memungkinkan untuk mencapai kinerja yang lebih baik.

Sejalan dengan itu, penelitian terbaru seperti Sadikoglu and Zehir (2010) menemukan bahwa kinerja inovasi memiliki dampak yang signifikan dan positif terhadap kinerja perusahaan di Turki yang memiliki sertifikat ISO 9001 dan 2000. Liao et al. (2010) menyimpulkan bahwa kecepatan inovasi memiliki pengaruhi positif dan signifikansi terhadap kinerja perusahaan. Vaccaro, Parente, and Veloso (2010) dan penelitian Rajapathirana and Hui (2018) menunjukkan hubungan yang kuat antara kemampuan berinovasi dan kinerja bisnis yang diuji pada industri asuransi di Sri Lanka.

H3: Terdapat hubungan yang postif antara inovasi produk dengan kinerja bisnis perusahaan.

\section{METODOLOGI PENELITIAN}

\subsection{Populasi \& Sampel}

Populasi penelitian ini adalah UKM yang bergerak pada sektor industri mesin dan pengecoran logam dengan responden pemilik atau pengelola usaha. Jumlah populasi sebanyak 3.105 yang terdiri dari 2.932 UKM di Kabupaten Tegal dan 173 UKM di Kabupaten Klaten.

Dipilihnya sektor industri ini karena karakteristiknya yang sesuai dengan topik dan tujuan penelitian. Industri logam di Kabupaten Tegal dan Kabupaten Klaten yang sebagian besar merupakan usaha skala kecil dan menengah (UKM) memiliki produk yang cenderung terdiversifikasi dan dinamis mengikuti dinamika pasar. Alasan lain dipilihnya sektor UKM ini karena tingkat inovasi pada industri logam di Kabupaten Tegal cukup tinggi. Hal ini bisa dilihat dari beragam produk yang dihasilkan. Pelaku industri sangat kreatif dalam melakukan imitasi terhadap berbagai jenis produk logam yang didukung oleh keahlian, peralatan, serta institusi pendukung, yaitu Pusat Pengembangan Inovasi dan Teknologi (PPIT) yang terdiri dari Laboratorium Uji Material, Klinik HaKI, show room, market center, dan Klinik Konsultasi Bisnis $(\mathrm{KKB})$. 
Metode pemilihan sampel dilakukan dengan metode non-random sampling dengan teknik purposive sampling. Teknik pengambilan sample ini dilakukan dengan menetapkan kriteria pada sample penelitian, antara lain: usaha bergerak disektor logam, responden adalah pemilik atau manajer usaha, pengalaman kerja lebih dari 5 tahun, serta membawahi sekurang-kurangnya 2 karyawan dibidang produksi. Ukuran sampel yang akan digunakan untuk kepentingan analisis dengan menggunakan Structural Equation Modeling (SEM) adalah berkisar antara 100 sampai dengan 200, Hair (1995). Sedangkan teknik pengumpulan data dilakukan dengan cara wawancara langsung dengan pemilik dan atau pengelola perusahaan menggunakan instrumen berupa kuesioner.

Untuk mendapatkan data penelitian yang diharapkan, disebarkan 205 kuesioner dengan rincian 125 kuesioner untuk UKM di Kabupaten Tegal dan 80 kuesioner untuk Kabupaten Klaten, kuesioner yang kembali sebanyak 197 kuesioner. Setelah dilakukan pengecekan, terdapat 7 kuesioner yang tidak memenuhi syarat, dan 11 kuesioner dinyatakan outlier, sehingga data yang dapat diproses analisis sebanyak 179 kuesioner.

\subsection{Variabel}

Terdapat tiga variabel dalam penelitian ini, pertama adalah experiential sharing merupakan aktivitas yang dilakukan oleh individu untuk berbagi pengalaman dan keterampilan yang bersifat tacit kepada individu lain dalam perusahaan. Variabel kedua adalah inovasi produk yang berkaitan dengan kegiatan yang memproduksi barang baru untuk menciptakan pasar atau pelanggan baru atau memuaskan pasar atau pelanggan saat ini. Variabel ketiga adalah kinerja bisnis yakni keberhasilan yang dicapai oleh perusahaan yang ditandai oleh keberhasilan dalam mencapat tujuan dan efisiensi dalam operasi bisnis perusahaan. Bersumber dari beberapa kajian teoritis dan penelitian empiris, berikut disajikan indikator masing variabel penelitian, pada tabel 4.1 bawah ini: 
Tabel 4.1. Indikator Penelitian

\begin{tabular}{|c|c|c|}
\hline Variabel & Indikator/Simbol & Sumber Referensi \\
\hline $\begin{array}{l}\text { Experiential } \\
\text { Sharing }\end{array}$ & $\begin{array}{l}\text { 1. Berbagi pengalaman kegagalan masa lalu } \\
\text { (ES11) } \\
\text { 2. Berbagi pengetahuan ber-dasarkan pengalaman } \\
\text { (ES12) } \\
\text { 3. Menimba pengetahuan berdasarkan pengalaman } \\
\text { karyawan lain (ES13) } \\
\text { 4. Berbagi pengetahuan berdasarkan keahlian } \\
\text { (ES14) } \\
\text { 5. Berbagi pengalaman kesuk-sesan masa lalu } \\
\text { (ES15) } \\
\text { 6. Menimba pengetahuan berdasarkan pengalaman } \\
\text { pimpinan (ES16) } \\
\text { 7. Menimba pengetahuan dari pengalaman } \\
\text { karyawan eksternal (ES 17) }\end{array}$ & $\begin{array}{l}\text { (Hooff \& Weenen, 2004; } \\
\text { Kc, Staats, \& Gino, 2013; } \\
\text { Wang \& Wang, 2012; Wu } \\
\text { \& Cheng, 2018) }\end{array}$ \\
\hline Inovasi Produk & $\begin{array}{l}\text { 1. Senantiasa membuat produk baru yang } \\
\text { memudahkan dalam penggunaan (IP23) } \\
\text { 2. Senantiasa mengembangkan produk baru } \\
\text { dengan bahan baku yang berbeda (IP24) } \\
\text { 3. Membuat produk baru dengan spesifikasi teknis } \\
\text { dan fungsi produk yang berbeda (IP25) } \\
\text { 4. Senantiasa memperkenalkan produk baru } \\
\text { dengan kualitas yang lebih baik.(IP26) } \\
\text { 5. Produk yang diperkenalkan selalu berbeda } \\
\text { dengan pesaing (IP27) } \\
\text { 6. Seringkali membuat produk dengan model baru } \\
\text { sesuai dengan pesanan pelanggan (IP28) }\end{array}$ & $\begin{array}{l}\text { (Atalay et al., 2013; Lin, } \\
\text { 2007; Rajapathirana \& } \\
\text { Hui, 2018; Soto-Acosta et } \\
\text { al., 2017; West, 1990) }\end{array}$ \\
\hline Kinerja Bisnis & $\begin{array}{l}\text { 1. Pertumbuhan penjualan (KB29) } \\
\text { 2. Nilai Penjualan (KB30) } \\
\text { 3. Peningkatan laba (KB31) } \\
\text { 4. Pertumbuhan modal (KB32) }\end{array}$ & $\begin{array}{l}\text { (Atalay et al., } 2013 \text {; } \\
\text { Calantonea et al., } 2002 \text {; } \\
\text { Liao et al., } \\
\begin{array}{l}\text { 2010; } \\
\text { Rajapathirana \& }\end{array} \\
\text { 2018) }\end{array}$ \\
\hline
\end{tabular}

Sumber : dari berbagai studi empirik 


\subsection{Pengujian Instrumen Penelitian}

Dilakukan tiga pengujian validitas intrumen dengan menggunakan pendekatan SmartPLS atau disebut uji outer model yang terdiri dari Convergent Validity, Discriminant Validity, Cronbach Alfa dan Composite reliability (Chin dalam Ghozali, 2011). Pengujian dilakukan secara iteratif sampai mendapatkan parameter yang memenuhi syarat. Terdapat 3 indikator experietial sharing dan 2 indikator inovasi produk yang didrop karena tidak memenuhi syarat parameter uji outer model. Berikut hasil pegujian pada model pengukuran yang telah memenuhi syarat pengujian.

\section{Convergent Validity}

Data yang digunakan dalam uji Convergent Validity sebanyak 179 unit data. Hasil pengujian validitas konvergen pada tabel 4.2 menunjukkan nilai AVE dan communality seluruh konstruk penelitian lebih besar dari 0,5.

Tabel 4.2. Average Variance Extracted (AVE) dan Communality

\begin{tabular}{lll}
\hline \hline Konstruk & AVE & Communality \\
\hline Business Performence (KB) & 0,933606 & 0,992765 \\
Experiential sharing (ES) & 0,762772 & 0,959739 \\
Product Innovation (IP) & 0,605703 & 0,946246 \\
\hline
\end{tabular}

Sumber: data primer (diolah, 2018)

Pada tabel 4.3 menunjukkan nilai outer loading tiap-tiap indikator penelitian telah memenuhi parameter validitas konvergen yaitu diatas 0,7 , sehingga model pengukuran dapat dinyatakan layak.

Tabel 4.3. Outer loading Model Pengukuran

\begin{tabular}{llll}
\hline \hline Indikator & $\begin{array}{l}\text { Business } \\
\text { Performence } \\
(\text { KB })\end{array}$ & $\begin{array}{l}\text { Experiential } \\
\text { Eharing }(\text { ES })\end{array}$ & $\begin{array}{l}\text { Product } \\
\text { Innovation } \\
\text { (IP) }\end{array}$ \\
\hline ES19 & & 0,784102 & \\
ES20 & & 0,844527 & \\
ES21 & & 0,997003 & \\
ES22 & & 0,853833 & \\
IP24 & & & 0,812989 \\
IP25 & & 0,788871 \\
IP26 & & & 0,725137 \\
IP28 & & & 0,783404 \\
\hline
\end{tabular}




\begin{tabular}{lll}
\hline \hline Indikator & $\begin{array}{l}\text { Business } \\
\text { Performence } \\
\text { (KB) }\end{array}$ & $\begin{array}{l}\text { Experiential } \\
\text { Eharing (ES) }\end{array}$ \\
\hline (IP) \\
Innovation \\
KB30 & 1,042971 & \\
KB31 & 0,920303 & \\
KB32 & 0,910116 & \\
\hline
\end{tabular}

\section{Discriminant Validity}

Pengujian validitas diskriminan dilakukan dengan menggunakan parameter cross loading diatas 0,6 sesuai dengan rule of thumb. Pengujian validitas diskriminan disajikan dalam tabel 4.4 sebagai berikut:

Tabel 4.4. Cross loading Model Pengukuran

\begin{tabular}{llll}
\hline Indikator & $\begin{array}{l}\text { Business } \\
\text { Performence } \\
\text { (KB) }\end{array}$ & $\begin{array}{l}\text { Experiential } \\
\text { Eharing } \\
\text { (ES) }\end{array}$ & $\begin{array}{l}\text { Product } \\
\text { Innovation (IP) }\end{array}$ \\
\hline ES19 & 0,235553 & $\mathbf{0 , 7 8 4 1 0 2}$ & 0,412537 \\
ES20 & 0,233936 & $\mathbf{0 , 8 4 4 5 2 7}$ & 0,509477 \\
ES21 & 0,306422 & $\mathbf{0 , 9 9 7 0 0 3}$ & 0,508864 \\
ES22 & 0,152860 & $\mathbf{0 , 8 5 3 8 3 3}$ & 0,307941 \\
IP24 & 0,299173 & 0,282675 & $\mathbf{0 , 8 1 2 9 8 9}$ \\
IP25 & 0,260301 & 0,304271 & $\mathbf{0 , 7 8 8 8 7 1}$ \\
IP26 & 0,205144 & 0,462432 & $\mathbf{0 , 7 2 5 1 3 7}$ \\
IP28 & 0,255900 & 0,491118 & $\mathbf{0 , 7 8 3 4 0 4}$ \\
KB29 & $\mathbf{1 , 0 4 2 9 7 1}$ & 0,346789 & 0,404792 \\
KB30 & $\mathbf{0 , 9 2 0 3 0 3}$ & 0,269144 & 0,317268 \\
KB31 & $\mathbf{0 , 9 1 0 1 1 6}$ & 0,172925 & 0,243823 \\
KB32 & $\mathbf{0 , 9 8 5 5 7 9}$ & 0,228428 & 0,241538 \\
\hline & & &
\end{tabular}

Hasil pengujian cross lading pada tabel 4.4 dan pengujian akar AVE, menunjukkan bahwa tidak terdapat cross loading dan nilai akar AVE seluruh konstruk lebih besar dari koefisien korelasinya. Sehingga dapat disimpulkan bahwa model pengukuran yang digunakan 
dapat dinyatakan telah memenuhi kriteria validitas diskriminan serta dinyatakan layak dan dapat digunakan untuk menguji model struktural.

\section{Cronbach alpha dan Composite reliability}

Untuk memastikan bahwa tidak ada masalah terkait pengukuran, maka langkah terakhir dalam evaluasi outer model adalah menguji unidimensionalitas dari model. Uji unidimensionality dilakukan dengan menggunakan indikator cronbach alpha dan composite reliability.

Hasil pengujian reliabilitas data menggunakan parameter Cronbach's alpha dan composite reliability pada tabel 4.5, menunjukkan bahwa seluruh konstruk memiliki nilai Cronbach's alpha diatas 0,6 dan composite reliability diatas 0,7. Dari hasil pengujian tersebut dapat dinyatakan bahwa data memiliki reliabilitas yang baik.

Tabel 4.5. Nilai Cronbach's alpha dan Composite reliability

\begin{tabular}{lrlll}
\hline \hline Konstruk & $\begin{array}{l}\text { Composite } \\
\text { reliability }\end{array}$ & R Square & $\begin{array}{l}\text { Cronbachs } \\
\text { Alpha }\end{array}$ \\
\hline $\begin{array}{l}\text { Business } \\
\text { (KB) }\end{array}$ & Performence & $\mathbf{0 , 9 8 2 4 7 9}$ & 0,122042 & $\mathbf{0 , 9 2 8 0 8 7}$ \\
$\begin{array}{l}\text { Experiential sharing (ES) } \\
\text { Product Innovation (IP) }\end{array}$ & $\mathbf{0 , 9 2 7 3 1 8}$ & & $\mathbf{0 , 7 2 2 9 9 1}$ \\
\hline
\end{tabular}

\section{PENGUJIAN MODEL STRUKTURAL}

Pengujian kelayakan model atau uji model struktural (inner model) dilakukan untuk melihat hubungan antar konstruk. Pengujian model struktural dilakukan dengan dua tahap. Pertama melakukan uji model hubungan langsung untuk seluruh konstruk independen yaitu Experiential sharing (ES), Inovasi Produk (IP), terhadap Kinerja Bisnis (KB). Tahap kedua, melakukan pengujian pengaruh mediasi. Pengujian ini dilakukan untuk mengetahui perubahan pengaruh langsung antara ES dengan KB setelah dimasukan variabel IP kedalam model. Pengujian ini menggunakan parameter nilai $t$-statistic yang harus diatas 1,96 untuk uji hipotesis dua ekor (two-tailed) dan atau diatas 1,64 untuk uji hipotesis satu ekor (one-tailed), pengujian hipotesis pada alpha 5 persen dan power 80 persen (Hair, et al.,2010). Hasil masing-masing tahapan tersebut dijelaskan pada bagian berikut ini: 


\subsection{Pengaruh Experiential sharing terhadap Kinerja Bisnis}

Pengujian hubungan langsung antara konstruk-konstruk independen dengan dependen dilakukan dengan teknik bootstrapping dibantu oleh perangkat lunak SmartPLS. Pengaruh langsung dan signifikansinya merupakan syarat pengujian mediasi, khususnya pengaruh langsung Experiential sharing (ES) terhadap Kinerja Bisnis (KB) dan pengaruh Inovasi Produk (IP) terhadap Kinerja Bisnis (KB). Koefisien kedua path tersebut akan berubah jika dimasukan pengaruh langsung dari Experiential sharing (ES) terhadap Inovasi Produk (IP). Perubahan sifat atau koefisien hubungan langsung pada model sebelumnya akan menentukan efek mediasinya. Ada pun hasil (output) proses bootstrapping pengujian hubungan langsung antar konstruk disajikan dalam gambar 4.6 sebagai berikut:

Tabel 5.1 Uji Hubungan Langsung ES terhadap KB

\begin{tabular}{|c|c|c|c|c|}
\hline Uji Model I & $\begin{array}{l}\text { Original } \\
\text { Sample } \\
\text { (O) }\end{array}$ & $\begin{array}{l}\text { Sample } \\
\text { Mean } \\
\text { (M) }\end{array}$ & $\begin{array}{l}\text { Standard } \\
\text { Deviation } \\
\text { (STDEV) }\end{array}$ & $\begin{array}{l}\text { Standard } \\
\text { Error } \\
\text { (STERR) }\end{array}$ \\
\hline \multirow{3}{*}{$\begin{array}{l}\text { Experiential sharing (ES) } \\
\text { Business Performance (KB) }\end{array}$} & 0,278702 & 0,299992 & 0,059362 & 0,059362 \\
\hline & \multicolumn{4}{|c|}{ T Statistics (|O/STERR|) } \\
\hline & 4,694939 & & & \\
\hline
\end{tabular}

Hasil pengujian pada model I menunjukkan nilai koefisien pengaruh Experiential sharing (ES) terhadap Kinerja Bisnis (KB) sebesar 0,2787 dengan nilai t-value sebesar 4,69 atau lebih besar dari pada 1,64 (uji satu sisi). Hal ini menunjukkan bahwa ES mempengaruhi KB secara positif dan signifikan.

\subsection{Pengaruh Experiential sharing terhadap Inovasi Produk}

Pengaruh langsung Experiential sharing (ES) terhadap Inovasi Produk (IP) dibuktikan dengan nilai koefisien path dan nilai $t$-value. Adapun hasil pengujian sebagai berikut:

Tabel 5.2 Uji Hubungan Langsung ES terhadap PI

\begin{tabular}{lllll}
\hline Uji Model II & $\begin{array}{l}\text { Original } \\
\text { Sample } \\
(\mathbf{O})\end{array}$ & $\begin{array}{l}\text { Sample } \\
\text { Mean } \\
(\mathrm{M})\end{array}$ & $\begin{array}{l}\text { Standard } \\
\text { Deviation } \\
\text { (STDEV) }\end{array}$ & $\begin{array}{l}\text { Standard } \\
\text { Error } \\
\text { (STERR) }\end{array}$ \\
\hline & $\mathbf{0 , 5 2 6 3 6 4}$ & 0,538433 & 0,048474 & 0,048474 \\
\cline { 2 - 4 } $\begin{array}{l}\text { Experiential sharing (ES) } \\
\text { Product Innovation (PI) }\end{array}$ & $-->$ & T Statistics (|O/STERR $\mid)$ & \\
\cline { 2 - 5 } & $\mathbf{1 0 , 8 5 8 6 1 0}$ & & \\
\hline
\end{tabular}


Hasil pengujian pada model II menunjukkan nilai koefisien pengaruh Experiential sharing (ES) terhadap Inovasi Produk (PI) sebesar 0,5264 dengan nilai t-value sebesar 10,86 atau lebih besar dari pada 1,64 (uji satu sisi). Hal ini menunjukkan bahwa ES mempengaruhi PI secara positif dan signifikan.

\subsection{Pengaruh Inovasi Produk terhadap Kinerja Bisnis}

Hasil pengujian pada model III menunjukkan nilai koefisien pengaruh Inovasi Produk (PI) terhadap Kinerja Bisnis (KB) sebesar 0,3271 dengan nilai $t$-value besar 4,96 atau lebih besar dari pada 1,64 (uji satu sisi). Hal ini menunjukkan bahwa PI mempengaruhi KB secara positif dan signifikan.

Tabel 5.3 Uji Hubungan Langsung PI terhadap KB

\begin{tabular}{|c|c|c|c|c|}
\hline Uji Model III & $\begin{array}{l}\text { Original } \\
\text { Sample } \\
(\mathbf{O})\end{array}$ & $\begin{array}{l}\text { Sample } \\
\text { Mean } \\
(\mathrm{M})\end{array}$ & $\begin{array}{l}\text { Standard } \\
\text { Deviation } \\
\text { (STDEV) }\end{array}$ & $\begin{array}{l}\text { Standard } \\
\text { Error } \\
\text { (STERR) }\end{array}$ \\
\hline \multirow{3}{*}{$\begin{array}{l}\text { Product Innovation (PI) - } \\
\text { Business Performance (KB) }\end{array}$} & 0,327058 & 0,346975 & 0,065954 & 0,065954 \\
\hline & \multicolumn{4}{|c|}{ T Statistics (|O/STERR|) } \\
\hline & 4,958844 & & & \\
\hline
\end{tabular}

\subsection{Peran Mediasi Inovasi Produk terhadap hubungan antara Experiential sharing dengan Kinerja Bisnis}

Setelah terbukti terdapat hubungan langsung antar variabel penelitian, selanjutnya dilakukan pengujian pengaruh mediasi berdasarkan model struktural (gambar 2). Berdasarkan output parameter uji signifikansi, pertama, hasil pengujian hubungan langsung melalui nilai path coeficient (tabel 4.9) dan kedua, hasil pengujian hubungan tidak langsung (indirect) disajikan dengan tabel total effect (tabel 4.10). 


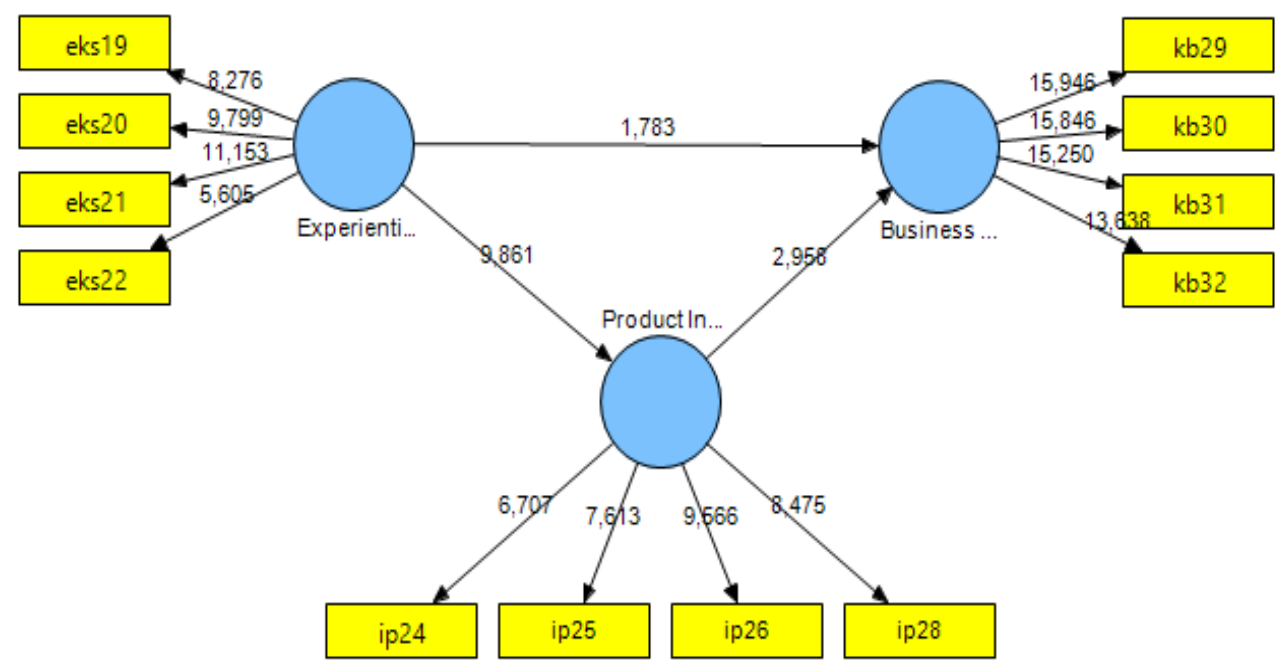

Gambar 4.1 Model Pengujian Struktural

Tabel 5.4 Tabel Pengaruh Langsung (Path Coefficients)

\begin{tabular}{|c|c|c|c|c|c|c|c|}
\hline Uji Model Struktural & & & & $\begin{array}{l}\text { Original } \\
\text { Sample } \\
(0)\end{array}$ & $\begin{array}{l}\text { Sample } \\
\text { Mean (M) }\end{array}$ & $\begin{array}{l}\text { Standard } \\
\text { Deviation } \\
\text { (STDEV) }\end{array}$ & $\begin{array}{l}\text { Standard } \\
\text { Error } \\
\text { (STERR) }\end{array}$ \\
\hline $\begin{array}{l}\text { Experiential sharing } \\
\text { Performence }(\mathrm{KB})\end{array}$ & (ES) & $-->$ & Business & 0,147398 & 0,154675 & 0,082656 & 0,082656 \\
\hline $\begin{array}{l}\text { Experiential sharing } \\
\text { Innovation }(\mathbf{P I})\end{array}$ & (ES) & $-->$ & Product & 0,513754 & 0,525825 & 0,052101 & 0,052101 \\
\hline $\begin{array}{l}\text { Product Innovation } \\
\text { Performence (KB) }\end{array}$ & (PI) & $-->$ & Business & 0,249926 & 0,254296 & 0,084503 & 0,084503 \\
\hline & & & & \multicolumn{4}{|c|}{ T Statistics (|O/STERR|) } \\
\hline $\begin{array}{l}\text { Experiential sharing } \\
\text { Performence }(\mathrm{KB})\end{array}$ & (ES) & $-->$ & Business & 1,783280 & & & \\
\hline $\begin{array}{l}\text { Experiential sharing } \\
\text { Innovation (IP) }\end{array}$ & (ES) & $->$ & Product & 9,860704 & & & \\
\hline $\begin{array}{l}\text { Product Innovation } \\
\text { Performence (KB) }\end{array}$ & (IP) & $->$ & Business & 2,957589 & & & \\
\hline
\end{tabular}


Tabel 5.5 Tabel Pengaruh Tidak Langsung (Total Effect)

\begin{tabular}{lllll}
\hline & $\begin{array}{l}\text { Original } \\
\text { Sample } \\
\text { (O) }\end{array}$ & $\begin{array}{l}\text { Sample } \\
\text { Mean (M) }\end{array}$ & $\begin{array}{l}\text { Standard } \\
\text { Deviation } \\
\text { (STDEV) }\end{array}$ & $\begin{array}{l}\text { Standard } \\
\text { Error } \\
\text { (STERR) }\end{array}$ \\
\hline $\begin{array}{l}\text { Experiential sharing (ES) } \\
\text { Business Performence (KB) }\end{array}$ & $\mathbf{0 , 2 7 5 7 9 9}$ & 0,286469 & 0,063457 & 0,063457 \\
$\begin{array}{l}\text { Experiential sharing (ES) } \\
\text { Product Innovation (PI) }\end{array}$ & $\mathbf{0 , 5 1 3 7 5 4}$ & 0,525825 & 0,052101 & 0,052101 \\
$\begin{array}{l}\text { Product Innovation (PI) --> } \\
\text { Business Performence (KB) }\end{array}$ & $\mathbf{0 , 2 4 9 9 2 6}$ & 0,254296 & 0,084503 & 0,084503 \\
\hline $\begin{array}{l}\text { T Statistics (|O/STERR|) } \\
\text { Experiential sharing (ES) --> } \\
\text { Business Performence (KB) }\end{array}$ & $\mathbf{4 , 3 4 6 2 5 1}$ & & & \\
$\begin{array}{l}\text { Experiential sharing (ES) } \\
\text { Product Innovation (PI) }\end{array}$ & $\mathbf{9 , 8 6 0 7 0 4}$ & & & \\
$\begin{array}{l}\text { Product Innovation (PI) --> } \\
\text { Business Performence (KB) }\end{array}$ & $\mathbf{2 , 9 5 7 5 8 9}$ & & & \\
\hline
\end{tabular}

Berdasarkan hasil analisis path coefficient dan total effects menunjukkan bahwa hubungan langsung experiential sharing (ES) terhadap kinerja bisnis (PB) menjadi tidak siginfikan pada uji hipotesis dua sisi, dengan nilai t-value 1,783 atau <1,96, tetapi masih dikatakan siginifkan pada uji hipotesis satu sisi, yakni >1,64. Namun demikian, nilai total effect hubungan antara experiential sharing dengan kinerja bisnis menunjukkan nilai yang signifikan. Sehingga dapat diintrepetasi bahwa mediasi ini hanya bersifat sebagian (partially-mediating). Mediasi penuh (fully mediating) terjadi jika pada total effects ditemukan hubungan ES terhadap KB menjadi tidak signifikan (Abdillah \& Hartono, 2014)

Model struktural dapat dievaluasi dengan menggunakan $R$-square $\left(\mathrm{R}^{2}\right)$ dan nilai koefisien path atau $t$-values tiap jalur untuk uji signifikansi dalam model struktural. Pada tabel 4.11 menunjukkan nilai $R^{2}$ masing-masing variabel dependen. Nilai $R^{2} K B$ sebesar 0,122042 . Nilai ini menunjukkan bahwa variabel dependen atau KB dapat diprediksi/dipengaruhi oleh ES dan PI sebesar 12,2\%, atau dengan kata lain 87,8\% kinerja bisnis dipengaruhi oleh variabel lain diluar ES dan PI. Sedangkan untuk PI dipengaruhi oleh ES sebesar 26,39\% atau 73,61\% dipengaruhi oleh variabel lain selain ES. 
Tabel 5.6 Pengaruh Variabel Independen terhadap Variabel Dependen dalam Model Penelitian (Nilai $R^{2}$ )

\begin{tabular}{lc}
\hline \hline & R Square \\
\hline $\begin{array}{l}\text { Business Performence (KB) } \\
\text { Experiential sharing (ES) }\end{array}$ & $\mathbf{0 , 1 2 2 0 4 2}$ \\
Product Innovation (IP) & $\mathbf{0 , 2 6 3 9 4 4}$ \\
\hline
\end{tabular}

\section{PEMBAHASAN}

\subsection{Pengaruh Experiential sharing terhadap Kinerja Bisnis}

Experiential sharing (ES) terbukti mempengaruhi kinerja bisnis (KB) secara postif dan signifikan. Hal ini menunjukkan bahwa setiap peningkatan upaya atau aktivitas experiential sharing dalam organisasi dapat meningkatkan kinerja bisnis, artinya semakin besar upaya perusahaan melakukan experiential sharing maka semakin tinggi kinerja bisnis perusahaan. Secara kontekstual, pada perusahaan-perusahaan pada industri logam telah melakukan aktivitas experiential sharing dan terbukti secara empiris dapat meningkatkan kinerja bisnis perusahaan. Kemampuan perusahaan dalam meningkatkan aktivitas experiental sharing akan membantu meningkatkan kinerja bisnis sebesar 0,278702 atau 27,8\%. Bagi perusahaan yang memiliki kemampuan dalam mengembangkan proses experiential sharing maka akan mampu menjaga kinerja bisnisnya, sehingga memiliki sustainabilitas yang lebih baik dibanding dengan perusahaan yang lainnya.

\subsection{Pengaruh Inovasi Produk terhadap Kinerja Bisnis}

Inovasi produk (IP) terbukti mempengaruhi kinerja bisnis (KB) secara postif dan signifikan, hal ini menunjukkan setiap peningkatan aktivitas inovasi produk dapat meningkatkan kinerja bisnis perusahaan, artinya semakin besar upaya perusahaan melakukan inovasi produk maka semakin tinggi kinerja bisnis perusahaan. Secara kontekstual, pada industri logam yang menjadi objek penelitian terbukti telah melakukan aktivitas inovasi produk yang dapat meningkatkan kinerja bisnis perusahaan. Kemampuan perusahaan dalam meningkatkan aktivitas inovasi produk akan membantu meningkatkan kinerja bisnis sebesar 0,327058 atau 32,7\%.

\subsection{Peran Mediasi Inovasi Produk terhadap hubungan antara Experiential sharing dengan Kinerja Bisnis}

Hasil uji struktural pengaruh mediasi inovasi produk menunjukkan bahwa pengaruh langsung experiential sharing terhadap kinerja bisnis mengalami perubahan. Hasil ini dapat dijadikan indikasi bahwa konstruk inovasi produk memiliki peran mediasi terhadap hubungan antara experiential sharing dengan kinerja bisnis perusahaan. Namun demikian, tingkat signifikansi pengujian masih relevan dengan pengujian satu sisi, artinya peran mediasi inovasi produk terbukti secara empiris memiliki pengaruh positif. Jika merujuk pada kaidah intrepetasi 
hasil pengujian peran mediasi, maka inovasi produk hanya mampu memediasi sebagian (partially mediated) hubungan antara experiential sharing dengan kinerja bisnis. Secara statistik, pengaruh experintial sharing dalam organisasi terhadap peningkatan inovasi produk yang mendorong peningkatan kinerja bisnis hanya sebesar 12,2\%, sedangkan pengaruh experiential sharing terhadap inovasi produk sebesar $26,4 \%$, sehingga pengaruh keduanya dalam kategori lemah.

\section{KESIMPULAN}

Aktivitas experiential sharing terbukti secara empiris dapat meningkatkan inovasi produk dan kinerja bisnis perusahaan. Oleh karenanya, perusahaan yang memiliki kemampuan untuk mengembangkan proses experiential sharing akan memiliki kemampuan dalam inovasi produk yang pada akhirnya akan meningkatkan kinerja bisnisnya. Selain itu, aktivitas inovasi produk memiliki peran mediasi parsial terhadap hubungan antara experiential sharing dengan kinerja bisnis perusahaan. Peran ini menunjukkan bahwa terdapat variabel lain yang mempengaruhi kinerja bisnis melalui inovasi produk. Atau dengan kata lain, bahwa inovasi produk bukan satusatunya faktor yang mampu meningkatkan kinerja bisnis, namun terdapat faktor lain yang mungkin lebih dominan untuk meningkatkan knerja bisnis.

\section{IMPLIKASI / KETERBATASAN DAN SARAN UNTUK PENELITIAN SELANJUTNYA}

Hasil penelitian ini memberikan arah bagi pelaku UKM untuk dapat menciptakan keunggulan bersaing dengan meningkatkan inovasi produknya. Guna pencapai keunggulan kompetitif tersebut melalui inovasi, para pengelola dan atau manajer UKM harus dapat menciptakan dan mendorong para pekerjanya untuk dapat saling berbagi pengalaman (mengembangkan experiential sharing) dengan kolega dan bawahannya, sehingga mampu meningkatkan kemampuan inovasi perusahaan.

Keterbatasan penelitian ini adalah mengukur tingkat inovasi produk hanya dengan intrepetasi dari pengelola usaha, baik dari pemilik maupun dari manajer usaha. Secara konseptual, inovasi juga dapat dirasakan oleh konsumen. Sehingga baiknya untuk mengukur inovasi juga melibatkan persepsi konsumen dengan menggunakan teknik dyadic measurement scale. Selain itu, agar inovasi produk sebuah perusahaan mampu mendorong tercapainya keunggulan bersaing, maka disarankan agar penelitian berikutnya berfokus pada determinan atau faktor-faktor yang dapat meningkatkan kemampuan inovasi perusahaan.

\section{REFERENSI}

Abdillah, W., \& Hartono, J. (2014). Partial Least Square (PLS). Yogyakarta: Andi.

Alam, I., Endres, S. P., Lee Endres, M., \& Chowdhury, S. K. (2007). Tacit knowledge sharing, self-efficacy theory, and application to the Open Source community. Journal of Knowledge Management, 11(3), 92-103. doi: 10.1108/13673270710752135

Alwis, R. S.-d., \& Hartmann, E. (2008). The use of tacit knowledge within innovative companies: knowledge management in innovative enterprises. Journal of Knowledge Management Decision, 12(1), 133-147.

Amabile, T. M., Conti, R., Coon, H., Lazenby, J., \& Herron, M. (1996). Assessing the work environment for creativity. Academy of Management Journal, 39, 54-84. 
Atalay, M., Anafarta, N., \& Sarvan, F. (2013). The Relationship between Innovation and Firm Performance: An Empirical Evidence from Turkish Automotive Supplier Industry. Procedia - Social and Behavioral Sciences, 75, 226-235. doi: 10.1016/j.sbspro.2013.04.026

Barnett, H. G. (1953). Innovation: The Basis of Cultural Change. New York, NY: McGraw-Hill.

Barney, J. B. (1991). Firm resources and sustained competitive advantage. Journal of Management, 17(1), 99-120.

Baum, J. A. C., \& Ingram, P. (1998). Survival-enhancing learning in the Manhattan hotel industry. Management Science, 44, 996-1016.

Berry, A., Rodriguez, E., \& Sandee, H. (2001). Small and Medium Enterprise Dynamics in Indonesia. Bulletin of Indonesian Economic Studies, 37, 363-384. doi: 10.1080/00074910152669181

Bilton, C., \& Cummings, S. (2010). Creative Strategy: Reconnecting Business and Innovation. West Sussex: Wiley \& Sons.

Bock, G. W., \& Kim, Y. G. (2002). Breaking the myths of rewards: An exploratory study of attitudes about knowledge sharing. Management Journal, 15(2), 14-21.

Calantonea, R. J., Cavusgila, S. T., \& Zhao, Y. (2002). Learning orientation, firm innovation capability, and firm performance. Industrial Marketing Management, 31(2002), 515-524.

Capron, L., \& Hulland, J. (1999). Redeployment of Brands, Sales Forces, and General Marketing Management Expertise Following Horizontal Acquisitions: A Resource-Based View. Journal of Marketing, 63(2), 41. doi: 10.2307/1251944

Damanpour, F. (1991). Organizational innovation: a meta-analysis of effects of determinants and moderators. Academy of Management Journal, 1(34), 555-590.

Davidson, C., \& Voss, P. (2002). Knowledge management: An introduction to creating

competitive advantage from intellectual capital. Orient Paperbacks, Auckland, New Zealand.

Dawson, R. (2001). Knowledge capabilities as the focus of organisational development and strategy. Journal of Knowledge Management, 4(4), 320-327.

Drucker, P. F. (1993). Managing for the future: The 1990s and beyond. New York: Truman Talley Books/Plume.

Earl, M. (2001). Knowledge Management Strategies: toward a taxonomy. Journal of Management Information Systems, 18(1).

Fahy, J. (2000). The Resource-based view of the Firm: Some Stumbling-blocks on the Road to Understanding Sustainable Competitive Advantage. Journal of European Industrial Training, 24(2,3,4), 94-104.

Ganika, G. (2016). Keterkaitan antara orientasi rantai pasok, berbagi informasi dan kepuasan interrelasi antar perusahaan. SEGMEN Jurnal Manajemen dan Bisnis, 12(1).

Gino, F., Argote, L., Spektor, E. M., \& Todorova, G. (2010). First, get your feet wet: The effects of learning from direct and indirect experience on team creativity. Organizational Behavior and Human Decision Processes, 111, 102-115.

Hair, J., Anderson, R., Tathan R., and Black. (1995). Multivariate Data Analysis With Reading (Fourt edition ed.): Prentice Hall International Edition.

Handtrack, C. (2009). Knowledge Management and its Implications for Strategic Management in Organisations. (Doctor of Philosophy), Lincoln University New Zealand, New Zealand 
Hargadon, A., and Sutton, R. (1997). Technology brokering and innovation in a product development firm. Administrative Science Quarterly, 42(4), 716-749.

Helfat, C. E., \& Peteraf, M. A. (2003). The dynamic resource-based view: capability lifecycles. Strategic Management Journal, 24(10), 997-1010. doi: 10.1002/smj.332

Hendry, H., \& Erwin, H. (2014). The Impact of Knowledge Management and Entrepreneur's Knowledge on Innovation and Firm Performance. Journal the Winners: Economics, Business, Management, and Information System Journal, Vol 15, Iss 2, Pp 108-114 (2014)(2), 108. doi: 10.21512/tw.v15i2.624

Hogel, M., Parboteeah, K.P., and Munson, C.L. (2003). Team-level antecedents of individuals' knowledge networks. Decision Sciences, 34(4), 741-770.

Hooff, B., \& Weenen, F. (2004). Committed to share: Commitment and CMC use as antecedents of knowledge sharing. Knowledge and Process Management, 11, 13-24. doi: $10.1002 / \mathrm{kpm} .187$

Hult, G. T. M., Hurley, R. F., \& Knight, G. A. (2004). Innovativeness: its antecedents and impact on business performance. Industrial Marketing Management, 33(5), 429-438.

Hunt, S. D., \& Morgan, R. M. (1996). The resource-advantage theory of competition:Dynamics, path dependencies, and evolutionary dimension. Journal of Marketing, 60(4), 107-114.

Kakabadse, N. K., Kakabadse, A., \& Kouzim, A. (2003). Reviewing the knowledge management literature: towards a taxonomy. Journal of Knowledge Management, 7(4), 75-91.

Kamasak, R., \& Bulutlar, F. (2010). The influence of knowledge sharing on innovation. European Business Review, 22(3), 306-317.

Kc, D., Staats, B., \& Gino, F. (2013). Learning from My Success and from Others' Failure: Evidence from Minimally Invasive Cardiac Surgery. Management Science, 59, 2435-2449. doi: $10.1287 / \mathrm{mnsc} .2013 .1720$

Li, Y. H., Huang, J. W., \& Tsai, M. T. (2009). Entrepreneurial orientation and firm performance: The role of knowledge creation process. Industrial Marketing Management, 38, 440-449.

Liao, C., Wang, H.-Y., Chuang, S.-H., Shih, M.-L., \& Liu, C.-C. (2010). Enhancing knowledge management for R\&D innovation and firm performance: An integrative view. African Journal of Business Management, 4, 3026-3038.

Liebowitza, J., \& Megbolugbe, I. (2003). A set of frameworks to aid the project manager in conceptualizing and implementing knowledge management initiatives. International Journal of Project Management, 21, 189-198.

Lin, H. F. (2007). Knowledge sharing and firm innovation capability: an empirical study. International Journal of Manpower, 28(3/4), 315-332.

Mayfield, M. (2010). Tacit knowledge sharing: techniques for putting a powerful tool in practice. Development and Learning in Organizations: An International Journal, 24(1), 24-26. doi: 10.1108/14777281011010497

Nguyen, N. P., Ngo, L. V., Bucic, T., \& Phong, N. D. (2018). Cross-functional knowledge sharing, coordination and firm performance: The role of cross-functional competition. Industrial Marketing Management, 71, 123-134. doi: 10.1016/j.indmarman.2017.12.014

Nonaka, I., \& Takeuchi, H. (1995). The knowledge-creating company: How Japanese companies create the dynamic of innovation. New York, NY: Oxford University Press.

Nonaka, I., Toyama, R., \& Nagata, A. (2000). A firm as a knowledge-creating entity: a new perspective on the theory of the firm. Industrial and Corporate Change, 9, 1-20. 
Oke, A., Burke, G., \& Myers, A. (2007). Innovation types and performance in growing UK SMEs. International Journal of Operation and Production Management, 27(7), 735-753.

Penrose, E. T. (1959). The Theory of the Growth of the Firm: Basil Blackwell.

Polanyi, M. (1962). Personal Knowledge: Toward a Post-critical Philosophy. University of Chicago: Martino Fine Books (December 4, 2013.

Rajapathirana, R. P. J., \& Hui, Y. (2018). Empirical paper: Relationship between innovation capability, innovation type, and firm performance. Journal of Innovation \& Knowledge, 3, 44-55. doi: 10.1016/j.jik.2017.06.002

Rothwell, R. (1991). External networking and innovation in small and medium sized manufacturing firm in europe. Technovation, 2, 93-112.

Sadikoglu, E., \& Zehir, C. (2010). Investigating the effects of innovation and employee performance on the relationship between total quality management practices and firm performance: An empirical study of Turkish firms. International Journal of Production Economics, 127(2010), 13-26.

Scarbrough, H. (2003). Knowledge management, HRM and innovation process. International Journal of Manpower, 24(5), 501-516.

Shankar, R., \& Gupta, A. (2005). Towards framework for knowledge management implementation. Knowledge and Process Management, 12(4), 259-277.

Soto-Acosta, P., Popa, S., \& Palacios-Marqués, D. (2017). Social web knowledge sharing and innovation performance in knowledge-intensive manufacturing SMEs. Journal of Technology Transfer, 42(2), 425-440. doi: 10.1007/s10961-016-9498-z

Stovel, M., \& Bontis, N. (2002). Voluntary turnover: knowledge management friend or foe? Journal of Intellectual Capital, 3(3), 303-322.

Subramaniam, M., \& Youndt, M. A. (2005). The influence of intellectual capital on the types of innovative capabilities. Academy of Management Journal, 48(3), 450-463.

Sveiby, K. E. (1997). The New Organizational Wealth: Managing and Measuring KnowledgeBased Assets. New York, NY: Berrett-Koehler.

Sveiby, K. E., \& Simon, R. (2002). Collaborative climate and effectiveness of knowledge work. Journal of Knowledge Management, 6(5), 420-433.

Thompson, V. A. (1965). Bureaucracy and innovation. Administration Science Quarterly, 5(1), 20.

Vaccaro, A., Parente, R., \& Veloso, F. M. (2010). Knowledge management tools, interorganizational relationships, innovation and firm performance. Technological Forecasting and Social Change,, 77, 1076-1089.

Wang, Z., Sharma, P. N., \& Cao, J. (2016). From knowledge sharing to firm performance: A predictive model comparison. Journal of Business Research, 69(10), 4650-4658. doi: https://doi.org/10.1016/j.jbusres.2016.03.055

Wang, Z., \& Wang, N. (2012). Knowledge sharing, inovation and firm performance. Expert Systems with Applications, 39 (2012), 8899-8908.

Wernerfelt, B. (1984). A Resource-Based View of the Firm. Strategic Management Journal, 5 , 171-180.

West, M. A., and Farr, J. L. (1990). Innovation at work (M. A. W. a. J. L. Farr Ed.). Chichester: John Wiley \& Sons, Ltd. 
Wheelen, T. L., Hunger, J. D., Hoffman, A. N., \& Bamford, C. E. (2014). Strategic management and business policy : globalization, innovation, and sustainability.

Wickramasinghe, N. (2003). Do we practise what we preach? Are knowledge management systems in practice truly reflective of knowledge management systems in theory? . Business Process Management Journal, 9(3), 295-316.

Wu, H.-C., Ai, C.-H., \& Chang, Y.-Y. (2019). What Drives Experiential Sharing Intentions Towards Motorcycle Touring? The Case of Taiwan. Journal of China Tourism Research, 1-30. doi: 10.1080/19388160.2019.1705955

Wu, H.-C., \& Cheng, C.-C. (2018). Relationships between technology attachment, experiential relationship quality, experiential risk and experiential sharing intentions in a smart hotel. Journal of Hospitality and Tourism Management, 37, 42-58. doi: 10.1016/j.jhtm.2018.09.003

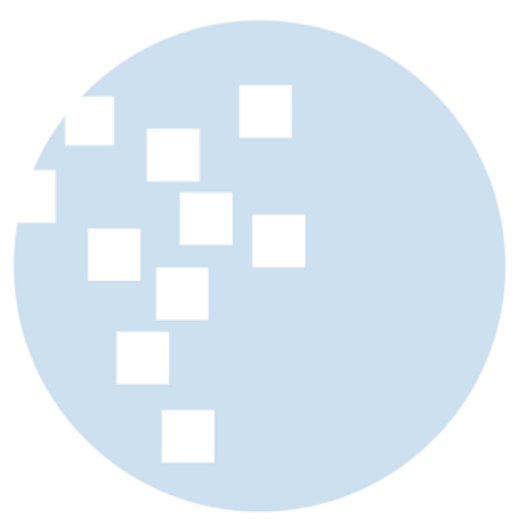

